\title{
Designing an agricultural system to enhance the quality of human life based on the capability approach
}

\section{Masahito Enomoto}

Policy Research Institute, Ministry of Agriculture, Forestry and Fisheries of Japan, 3-1-1 Kasumigaseki, Chiyoda-ku, Tokyo, 100-0013, Japan Email: menomoto2005@yahoo.co.jp

\begin{abstract}
An agricultural system can play multiple functions in enhancing the quality of human life. In the analysis of the relationship between an agricultural system and the quality of human life, socio-economic-environmental contexts play extremely important roles. The capability approach (CA) analyses human development with a keen interest in equity among people by using two aspects of freedom, 'well-being freedom' and 'agency freedom'. In this paper, we discuss how this approach will assist to analyse the processes involved in a sustainable agricultural practice to sustainably enhance people's well-being. To do so, the CA framework should be modified into a dynamic framework. Application of this framework to the sustainable agricultural practice of Sado Island, Japan, will show its usefulness in investigating different manifestations of capability among varied farmers and aiding stakeholders to collectively deliberate desirable capability changes and intervention plans. Eventually, it will contribute to fair and sustainable management of agricultural systems.
\end{abstract}

Keywords: well-being freedom; agency freedom; collective agency; capability approach dynamic framework; sustainability; sustainable agricultural system; Sado agriculture; crest ibis; capability approach.

Reference to this paper should be made as follows: Enomoto, M. (2020) 'Designing an agricultural system to enhance the quality of human life based on the capability approach', Int. J. Sustainable Design, Vol. 3, No. 4, pp.251-278.

Biographical notes: Masahito Enomoto is the Deputy Director General of the Policy Research Institute, Ministry of Agriculture, Forestry and Fisheries of Japan. Previously, he worked for Japan International cooperation Agency as Vice President for food, agriculture and nutrition. His research works are mainly in the area of policies on human development, human health and nutrition and sustainable agriculture.

\section{Introduction}

An agricultural system in a watershed (ASW), such as rice paddy systems in Japan and other countries, can play multiple roles in enhancing the quality of human life, if it is appropriately designed and managed. In the analysis of the relationship between an agricultural system and quality of human life, socio-economic-environmental contexts 
play important roles. In 2015, the sustainable development goals (SDGs) reaffirmed the multiple significant roles of an agricultural system, not only for development in monetary terms, but also for promoting equity and environmental sustainability. The capability approach (CA) of Amartya Sen analyses development with a keen interest in equity among people by using two aspects of freedom: 'well-being freedom', to live a life which an individual has reason to value, and 'agency freedom', to exert an action including a non-self-regarding action which an individual has reason to value. In this paper, we argue that this approach will assist to analyse the processes in which an agricultural system in a watershed develops to sustainably enhance the quality of human life. Here, an ASW is defined as a system in which farmers engage in agriculture within a watershed which results in the generation of various goods and services in interplay with other stakeholders and through interactions with the natural and social environment.

We start by briefly reviewing the different dimensions of development which are expected of agricultural systems by the SDGs. After that, Amartya Sen's CA is examined. Then, the shortcomings of the CA, such as its insufficient consideration of dynamics in which an individualistic freedom interacts with the external environments, are investigated based on recent studies. To address the shortcomings, the CA framework will be modified into a dynamic conceptual framework. Each step of this dynamic framework is described through a brief microeconomics model. Then, this framework is applied to the analysis of the ASW of Sado Island in Japan, where people promote the management of an ASW in alignment with the ecosystem. Based on information from semi-structured interviews and public documents related to Sado ASW, the CA dynamic framework is examined for its advantages and challenges in designing and analysing an ASW for the sustainable enhancement of people's quality of life.

\section{Multiple roles of ASWs in different dimensions}

\subsection{Multiple roles of ASWs and efforts to revive these roles}

ASWs, such as a rice paddy system, under proper management and appropriate conditions function as surrogates for natural wetlands (Bambaradeniya et al., 2003; Elphick, 2000; Endo and Nagata, 2013). Rice paddy fields often located in watersheds provide rice, the staple diet for nearly three billion people in the world, as well as fodder, fish, and other crops for both subsistence and commercial farming. Like natural wetlands they also provide functions such as flood control, water purification and ground water recharge (Ogawa and Sakai, 1985; Yamane et al., 2003). In addition, rice paddy fields such as the Banaue Rice Terraces of the Philippines or the Hongue Hani Rice Terraces of China impress us with their aesthetic charm in a cultural landscape (UNESCO World Heritage List, https://whc.unesco.org/en/list/722, https://whc.unesco.org/en/list/1111).

While the application of modern technology in agriculture has dramatically improved production and productivity, high-external input and resource-intensive agricultural systems have raised concerns on biodiversity loss and degradation of soil and water, in both developing and developed countries. Against such a drawback, there are a variety of activities that explore redesigning agricultural systems into more sustainable alternatives in consideration of ecosystems and surrounding environments. 


\subsection{Expectations from ASWs by the SDGs}

While the multiple roles of an ASW have been broadly recognised through research and targeted as a focus of several policies, international society calls for renewed efforts to fight against the global challenges to sustainable development. On September 25th, 2015, UN member countries adopted the SDGs. The 17 goals address a wide range of global issues with 169 specific targets to be achieved by 2030. Agriculture has a primary relation with Goal 2 which states: "End hunger, achieve food security and improved nutrition, and promote sustainable agriculture." Thus, Goal 2 and its targets (from 2.1 to 2.5) are evaluated to understand what is expected from agriculture in the context of the SDGs.

\subsection{Development of ASWs in different dimensions}

The development of ASWs may be addressed by referencing different dimensions detailed within the SDGs. In Goal 2 and its targets, three main dimensions are highlighted. Firstly, an 'economic dimension' is described. 'Food' (Target 2.1), 'production' (Target 2.4), 'productivity' (Targets 2.3 and 2.4) and 'income' (Target 2.3) are economic indicators related to people's satisfaction, desire fulfilment, or utility. Since agriculture is regarded as an economic activity, production quantity/value, various indicators of productivity (e.g., yield per hectare), and income levels are the main analytical data collected, as in the statistical reports of the World Bank and national governments. They are also traditionally primary targets in policies. However, from the viewpoint of the 'causal relationship', they are just tools or means to achieve other targets in Goal 2: 'end hunger' and 'end malnutrition' (Targets 2.1 and 2.2). When people living far from markets eat food which they grow, the economic dimension may become irrelevant, and through practices of subsistence they could achieve the same goals.

Secondly, a 'social dimension' is found. This dimension calls for 'equity' in accessing food as well as opportunities and resources - including water, knowledge, market, and financial services - among the poor and the vulnerable, including infants, children, women, indigenous peoples and small farmers (Targets 2.1, 2.2 and 2.3).

Thirdly, a 'sustainability dimension' is found in Goal 2. This aims at 'sustainable' food production to 'help maintain ecosystems' and 'strengthen the capacity for adaptation' against climate change, drought, flooding and so on (Target 2.4). However, because it aims to increase productivity and production, we may face 'trade-offs' between the economic dimension and the sustainable one.

\subsection{Necessity of a framework to analyse people's varied well-being while considering equity and sustainability}

Although three dimensions, 'economic', 'social' and 'sustainable' have been identified in Goal 2, some elements in the targets may have 'causal relationships' to the process of enhancing people's varied 'well-being'; while others are 'trade-offs'. It can be easily imagined that if we try to integrate Goal 2 with other goals such as 'water' (Goal 6), 'decent work' (Goal 8) and 'biodiversity' (Goal 15), the discussion will get complicated. Yet, as written in the Preamble and Paragraph 5 of the resolution, the 17 SDGs and 169 targets are 'integrated and indivisible' and 'balance the three dimensions of sustainable development': the economic, social and environmental. 
The question we ask is whether, when we design and manage ASWs which can play multiple roles in people's lives while at the same time considering equity and sustainability as proposed by the SDGs, there is any useful framework to capture all of these components. If such a framework were to exist as a common base among researchers, policy makers and practitioners, it would aid in identifying a desirable balance for designing and managing ASWs and would consequently support the SDGs intention of integrated and balanced sustainable development.

\section{Methodology}

To consider a conceptual framework to analyse how ASWs contribute to the enhancement of human well-being, quality of life, equity among people, and sustainability, the CA of Amartya Sen is examined, which analyses well-being freedom to live a life that an individual has reason to value, as well as agency freedom to pursue the goals an individual has reason to value. Then, its shortcomings such as insufficient explication of the relationship between individualistic freedom and external environments are examined on the basis of recent studies. By including the two streams resulting from well-being freedom and agency freedom into the static framework of the CA, a dynamic framework is presented. In addition, with a brief model based on microeconomics, each step in the dynamic framework is explicated.

Following this, the framework is applied to the analysis of the case of Sado Island in Japan, where farmers, citizens, governments, researchers, and NGOs are engaged in elaborate management of an ASW. Based on the information from semi-structured interviews and public documents, the CA dynamic framework is examined in the context of Sado ASW on its effectiveness to analyse and improve a sustainable practice of ASWs for enhancing the well-being of people while fairly allocating well-being within and between generations. Through the analysis, the advantages and limitations of applying the CA dynamic framework in the analysis of ASWs are discussed.

\section{The CA}

\subsection{Functionings and capability}

For the last several decades, the CA has played an important role as a normative framework for the evaluation of human development and the designing of developmental policies and equitable social systems. The core concept was developed by Sen (1985a, 1985b, 1992, 1999) (winner of the 1998 Nobel Prize for Economics), enhanced in collaboration with other scholars, especially with Philosopher Nussbaum (2000, 2011), and formed the basis for the human development index (HDI).

The core characteristic of the CA is its focus on the freedom to live a life that an individual has reason to value. What an individual values to do and to be are defined as 'functionings' [Sen, (1985a), p.10]. Functionings may include such things as 'being adequately nourished', 'having mobility', 'taking part in the life of a community', 'having self-respect', 'living in harmony with nature' and so on. This aids in capturing something that an individual values in his or her life not easily acquired through 
monetary terms. Robeyns (2005, p.98) displays a 'non-dynamic representation' of an individual's capability set in his or her social and personal contexts.

Figure 1 A non-dynamic representation of an individual's capability set and his or her social and personal context

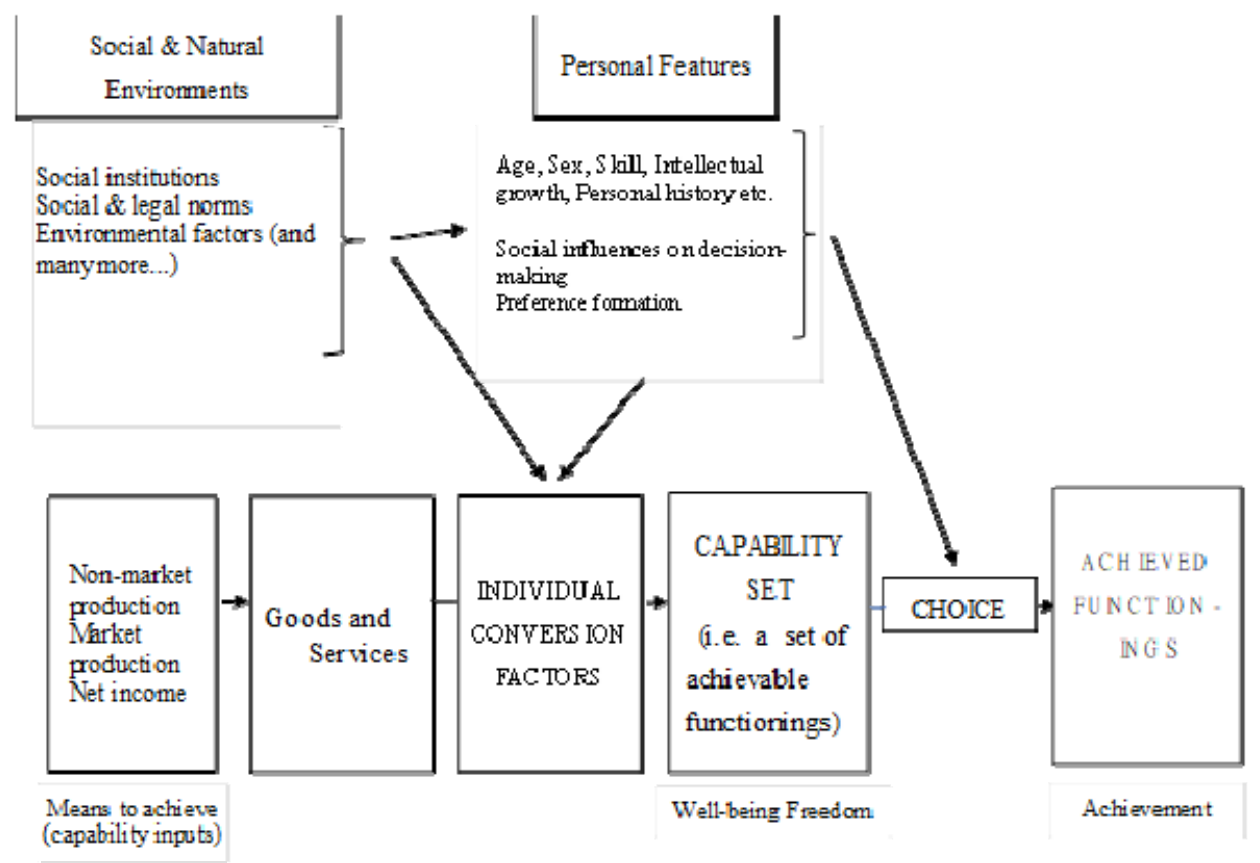

Source: Based on Robeyns (2005)

The CA also defines the concept of 'capability' which is a set of achievable functionings. In other words, capability is 'well-being freedom' with which an individual enjoys leading a life he or she values.

One of the distinctive features of the $\mathrm{CA}$ is its focus on the individual. Each individual is put in different natural and social environments. Each has different abilities to access a share of goods and services not only from the legal entitlement aspect but also from broader social, economic, and natural settings (e.g., entitlements to land or water use, intrahousehold rules) (Devereux, 2001; Sen, 1981).

Even when individuals have access to these capability inputs, they have different abilities to convert them into functionings (conversion factors). Conversion factors depend on the features of an individual's external environment such as social norms, infrastructure and nature, and this individual's personal features, such as age, sex, physical condition and intellectual growth.

The CA concept of 'well-being freedom' contrasts with traditional economic theories which focus on level of satisfaction or utility through goods and services, or a monetary value of goods and services such as 'the gross domestic product' and 'consumption' [Sen, (1999), p.3; (2013), p.12]. Although well-being freedom has intrinsic value as an end, goods and services have only instrumental value as a means. In addition, the CA points out that 'utility' is unreliable as a measurement because a continuously deprived person 
in poverty easily reconciles his or her utility with the adverse circumstances, which is regarded as 'adaptive preference' [Nussbaum, (2011), p.83].

\subsection{Agency freedom}

Another important concept in the CA is 'agency freedom', which refers to "what an individual is free to do and achieve in the pursuit of goals" that he or she values and has reason to value [Sen, (1985b) p.203]. An action based on agency motivated by 'commitment' is not necessarily beneficial to an individual's well-being [Robeyns, (2005), p.102]. It may include such actions as helping other people at the 'risk' of his or her own life. Agency freedom not only has intrinsic value in itself, but also instrumental values to bring about results and constructive values to affect value systems and the priorities of an individual and a society (Alkire, 2002; Crocker, 2006; Sen, 1999).

\subsection{Well-being generated from ASWs}

According to the CA, 'well-being freedom' and 'agency freedom' are assumed to be constituents in evaluating aspects of the human condition (Crocker, 2008; Gasper, 2002; Gotoh, 2002; Sen, 1985b) and may provide a framework to analyse the multiple roles of ASWs in the enhancement of quality of life. The CA will help to identify various opportunities that ASWs can produce for an individual to enhance his or her well-being. In the utility approach, the information tends to be limited to monetary terms or the opulence of goods from ASWs (e.g., income, volume of production). However, a farmer may give priority to ecological concerns over crop yields or may dedicate his or her life to conserve the local landscape. Some functionings may not be commensurable with income and production, and thus, could be overlooked.

\subsection{Equity and capability}

The next question we must ask is how to analyse equity? Since we identify well-being generated from ASWs with capability as a common currency, it is logical to analyse equity by the fairness of distribution of capabilities among people, not by the distribution of goods and services or of income (Sen, 1992). For instance, if a women's group cannot join local eco-tourism activities because of customs thwarting women's social participation, the capabilities of the group would be constrained. To judge if there is fair distribution of capabilities, it is necessary to investigate whether external environments or an individual's features affect conversion factors in a manner which constrains his or her creation of capability that could be achievable by others in the community.

\subsection{Sustainability and capability}

It was more than 30 years ago when the Brundtland Report defined sustainable development as "development that meets the needs of the present without compromising the ability of future generations to meet their own needs." (The World Commission on Environment and Development, 1987). Sen argues that a concept of sustainability has to aim at sustainable human freedom rather than being led by their own needs (Sen, 2004). Then, Sen (2013, p.11) redefines sustainable development as "development that prompts 
'the capabilities' of present people without compromising the 'capabilities' of future generations."

If sustainability is defined through capabilities as Sen does, then the next question is how the CA aids to observe processes in which actions based on freedom of the present generation are linked to the capabilities of future generations and how the processes should work for the continuous enhancement of people's capabilities.

\subsection{Connecting the CA to the notion of sustainability}

In regard to the relationship between the CA and sustainability, critiques point to several shortcomings in the CA. The first point is about its insufficient explication on the relationship between freedom at an individual level and external environments at a system level. This is beyond the scope of the Robeyns' (2005) representation. Lessmann and Rauschmayer (2013) explain the accumulation process in which achieved functionings at an individual level impact on natural and social environments at a system level and indicate the necessity of 'collective institutions' which reflect individuals' concern for sustainability and the roles which agency could play in this regard. However, the explication of the processes in which individuals' actions are linked to collective institutions is left to further research.

To address this point, it is necessary to focus on both 'well-being freedom' and 'agency freedom' and examine two streams which come out from exertion of freedom of the two aspects. The first stream is related to how an individual's choice out of capability, or achieved functionings, affects external environments through accumulation (the stream of accumulated achieved functionings). For instance, each individual's choice to achieve specific functionings from an ASW by utilising resources (e.g., use of agricultural chemicals) will accumulatively impact the external environment of the individual (e.g., condition of soil, biodiversity). Since these consequences will influence goods and services which can be generated from an ASW and conversion factors, they would affect capability creation by future generations. Thus, the analysis of the first stream is important.

The second stream is related to how actions based on agency freedom in pursuit of an individual's goal will affect external environments, and especially social arrangements (the stream of agency development). In this stream, the other-regarding and constructive nature of agency will play a crucial role. Agency actions induced by commitment of farmers and others based on whatever moral principles (e.g., responsibility to the less powerful, nature's intrinsic value), may start with recognition of the state of affairs in external environments which result from accumulation of achieved functionings in the first stream (e.g., degradation of soil, changes in biodiversity). Some may get directly involved in actions to maintain valuable capabilities for the future; others may get involved rather indirectly with partial interest. Information sharing, mutual learning and participation in deliberation could "strengthen and extend direct agency, make indirect agency less indirect, and link direct and indirect agency" [Crocker, (2008), p.156].

This process may aid them to form 'collective agency' as Fukuda-Parr (2003) points out, "to participate in public decision making" at the community level. Then, they reach common understanding on priorities among capabilities and a possible solution for fair distribution of these capabilities to bring about changes in social arrangements (e.g., a rule on chemical use or eco-tourism). Since these changes affect the creation of capabilities by future generations, the analysis of the second stream is also important. 
The second critique points to an ambiguous mechanism with which the CA adjusts distribution of freedoms between the present generation and future generations. Sen (2013, pp.13-18) argues, by comparing examples of declining fertility rates in several countries, 'education' and 'empowerment' of women and 'reasoning' as agents are more important for 'behavioural changes' towards sustainable development than 'coercion' which places constraints on freedom.

Regarding this, Holland (2008, p.416) interestingly proposed the notion of a 'capability ceiling' to alleviate inter-generational tensions in preserving people's valuable capabilities. This idea involves a coercive constraint on capabilities of the present generation (e.g., restricting the freedom to use water or chemicals), to prevent negative impacts on natural environments which may consequently lower valuable capabilities of future generations below threshold level.

Of course, the CA does not protect capabilities having obvious harmful effects on valuable capabilities of others (e.g., injuring people, racial discrimination). However, Sen puts priority on education and empowerment arguably to avoid inadvertently lowering people's freedom by using coercive measures without sound deliberation within a society.

The balanced choice between empowerment or adopting coercive measures will depend on context. For example, harmful chemicals such as persistent organic pollutants, which contaminate soil for a long time and constrain the capabilities of future generations, are prohibited by an international rule (The Stockholm Convention on Persistent Organic Pollutants, 2001). On the other hand, some farmers voluntarily lower the use of chemicals below the socially accepted levels to further enhance sustainability. To justly balanced intergenerational distribution of capabilities while enhancing people's freedom, if the possible harm to future generations' capabilities is regarded to be very minor, it would be better to refrain from coercive measures. Education and empowerment may be preferable in that they improve intergenerational balance through behavioural change. However, depending on characteristics of the capabilities at issue and the associated risk to future generations, coercive measures or less coercive measures, such as conditional financial support, will aid to adjust the intergenerational distribution of capabilities.

\subsection{Modification of a representation of the $C A$}

To analyse sustainable development in relation to an ASW based on the CA, an ASW needs to first be incorporated in the framework of the CA, then, it needs to be modified by reflecting on the two streams (the stream of accumulated achieved functionings and the stream of agency development) discussed in the previous sections. Thus, a conceptual framework of the CA with dynamics (the CA dynamic framework) for analysis of an ASW is presented in Figure 2. A brief explanation of the framework follows.

\subsubsection{Roles of external environments}

Generally, farmers and other stakeholders need to address various conditions from the external environments to formulate an ASW. An ASW consequently provides various capability inputs such as income from farming and eco-tourism, goods (e.g., rice, fodder), services (e.g., biodiversity, aesthetic landscape, culture, spaces for learning, occasions for self-realisation); some have strong affinities with a market system while some do not. 
These elements of the external environment, as discussed in the previous sections, may affect access to (Step 1) and conversion of (Step 2) capability inputs, and an extent of agency freedom (e.g., freedom of speech and public discussion). In addition, they may have influence on, or be internalised into, an individual's base for decision-making, consciously (e.g., through education, empowerment) or unconsciously (e.g., by influence of traditions, formation of adoptive preference).

Figure 2 A dynamic framework of capability and a food system

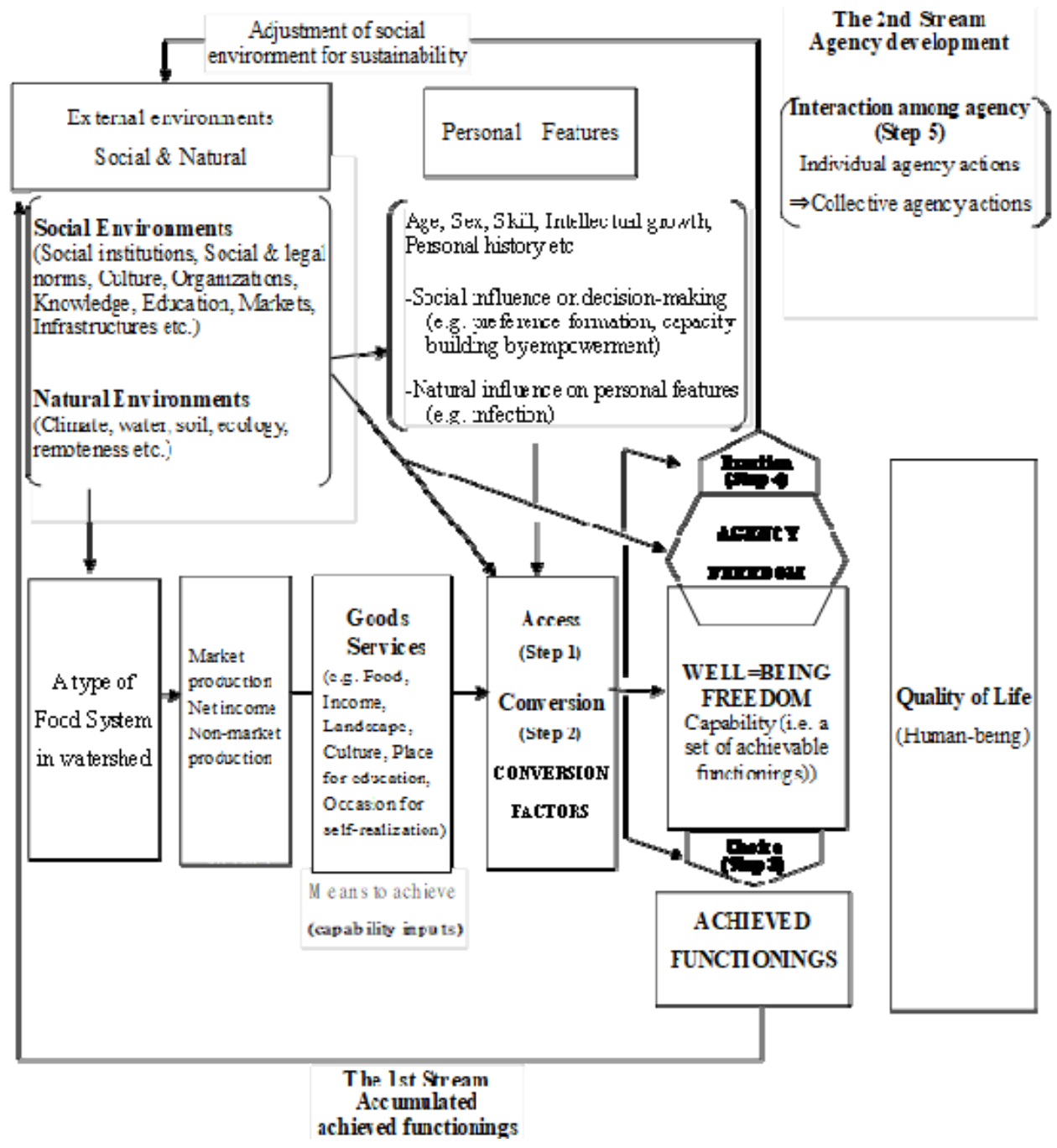

\subsubsection{Roles of personal features}

The elements of personal features (e.g., age, sex, skill, physical strength, intellectual growth) may affect an individual's 'access' to capability inputs generated by an ASW and an individual's 'conversion factors'. The personal features (e.g., sense of 
commitment or sympathy, sense of the good, sense of justice) may also affect an individual's 'choice behaviours' of functionings out of his or her capability (Step 3), or an individual's exertion of agency (Step 4).

\subsubsection{Accumulated achieved functionings - the first stream}

Achieved functionings at the individual level would affect external environments (social and natural) at a system level through accumulation.

\subsubsection{Development of agencies - the second stream}

An individual's agency actions may be triggered by his or her sense of commitment or sympathy in the face of a symptom of changes in the external environments, develop into an interaction of agency with others, and form collective agency to work for a shared goal, such as change of social arrangements for a fairer distribution of capabilities (Step 5).

\subsection{Investigation of each step of the conceptional framework with a simple model}

In several countries, it is not uncommon for farm communities to make efforts to change their practices from conventional commercial agriculture which mainly focuses on economic returns from an ASW by using standardised agricultural technology, a 'conventional agricultural practice' (CAP), to sustainable agriculture which focuses more on the ecosystem in farmland and surrounding areas to conserve an ASW for the future generation, a 'sustainable agricultural practice' (SAP). In this section, by using such a case, the meaning of each step in the CA dynamic framework shown in Figure 2 is further examined with a simple microeconomics model. As Gotoh (2014, pp.324-326) demonstrates, the idea of 'constrained optimisation' in economic theory is applied in a simple model by using an individual's valuation of capability instead of utility.

For simplification, a linear model is assumed in which a farmer creates capability by using two groups of capability inputs, one which could be evaluated in a market (e.g., crops, income) and the other which would not generally be evaluated in a market (e.g., biodiversity, aesthetic landscape, rural culture); the former is assumed to be generated from both a SAP and a CAP, and the latter only from a SAP. Although in certain instances a CAP might generate non-marketable capability inputs, it would be to a much lesser extent compared with a case of a SAP. Also, it is assumed that the constituents of the capabilities can be summable (e.g., by summing up evaluation scores). A farmer is expected to maximise the values of his or her choice from the capability frontier created from a SAP and a CAP under the limitation of his or her total assets.

Consider

$\mathrm{C}_{\mathrm{n}} \quad$ capability which a farmer creates with non-marketable capability inputs from a SAP (e.g., farming in aesthetic landscape or with strong social ties)

$\mathrm{C}_{\mathrm{m}} \quad$ capability which a farmer creates with marketable capability inputs from a SAP and a CAP (e.g., using income for farm equipment, selling rice for livelihood)

$\mathrm{C}\left(\mathrm{C}_{\mathrm{m}}, \mathrm{C}_{\mathrm{n}}\right)$ total capability which a farmer creates from farming (a capability frontier). 


$$
\mathrm{C}_{\mathrm{n}}=\mathrm{f}_{\mathrm{n}} \mathrm{A}_{\mathrm{s}}
$$

where $f_{n}$ is a conversion factor which transforms non-marketable capability inputs generated from one hectare of a SAP into capability

$$
\mathrm{C}_{\mathrm{m}}=\mathrm{f}_{\mathrm{ms}} \mathrm{A}_{\mathrm{s}}+\mathrm{f}_{\mathrm{mc}} \mathrm{A}_{\mathrm{c}}
$$

where $f_{m s}$ is a conversion factor which transforms marketable capability inputs generated from one hectare of a SAP into capability, and $f_{m c}$ is a conversion factor which transforms marketable capability inputs generated from one hectare of a CAP into capability

$\mathrm{p}_{\mathrm{s}}$ cost of production for one hectare of farmland under a SAP

$\mathrm{p}_{\mathrm{c}}$ cost of production for one hectare of farmland under a CAP

$\mathrm{A}_{\mathrm{s}}$ area of a SAP

$\mathrm{A}_{\mathrm{c}}$ area of a CAP

Y a farmer's total assets which can be appropriated for agriculture.

By choosing a set of functionings out of his capability, a farmer maximises value function of the form:

$$
\mathrm{V}=\mathrm{v}\left(\mathrm{C}_{\mathrm{m}}, \mathrm{C}_{\mathrm{n}}\right)
$$

where the partial derivative of $\mathrm{V}$ is non-negative, and $\mathrm{v}$ is strictly quasi-concave, subject to the resource constraint:

$$
\mathrm{p}_{\mathrm{s}} \mathrm{A}_{\mathrm{s}}+\mathrm{p}_{\mathrm{c}} \mathrm{A}_{\mathrm{c}} \leq \mathrm{Y}
$$

If this is solved by the method of Lagrange multiplier, a farmer maximises the value of capability from

$$
\frac{\partial v}{\partial C_{n}} / \frac{\partial v}{\partial C_{m}}=\frac{f_{m c} p_{s}}{f_{n} p_{c}}-\frac{f_{m s}}{f_{n}}=S
$$

This equation means that a farmer will maximise his or her capability value at $\mathrm{q}^{*}$ of Figure 3 where the indifferent value curve (IVC) and capability frontier with a line downwards to the right (ojkl) meet (except corner solutions of IVC 2 or IVC 3 which touch at the corners of a capability frontier). This case occurs when $\mathrm{S}$ in the equation is positive. (The case when $\mathrm{S}$ is negative will be examined later.) In this case, a farmer is facing a trade-off between two different types of capabilities which the farmer needs to balance. However, if the cost $\left(\mathrm{p}_{\mathrm{s}}{ }^{\prime}\right)$ of a SAP, say, for some minority group in the community happens to be higher than others' $\left(p_{s}\right)$ because of a community custom, it could mean that 'access to capability inputs' (Step 1) for the former is being constrained by the external environment and their capability frontiers could be receded from A (ojkl) to $A^{\prime}\left(o j k^{\prime} l^{\prime}\right)$, which means their well-being freedom is reduced. Also, as a point of contact may shift from $\mathrm{q}^{*}$ to $\mathrm{q}^{\prime}$ depending on the shapes of IVCs, their total value of achieved functionings are lowered and the area of SAP could also be lowered. From the viewpoint of both equity and sustainability, these situations would be better if adjusted. For instance, if the knowledge on a SAP is fully shared with the minority group in the 
community, their capability frontiers will be recovered and consequently enhance equity and sustainability.

Figure 3 Maximisation of capability value under the resource constraint, and a case of change in access (Step 1) (see online version for colours)

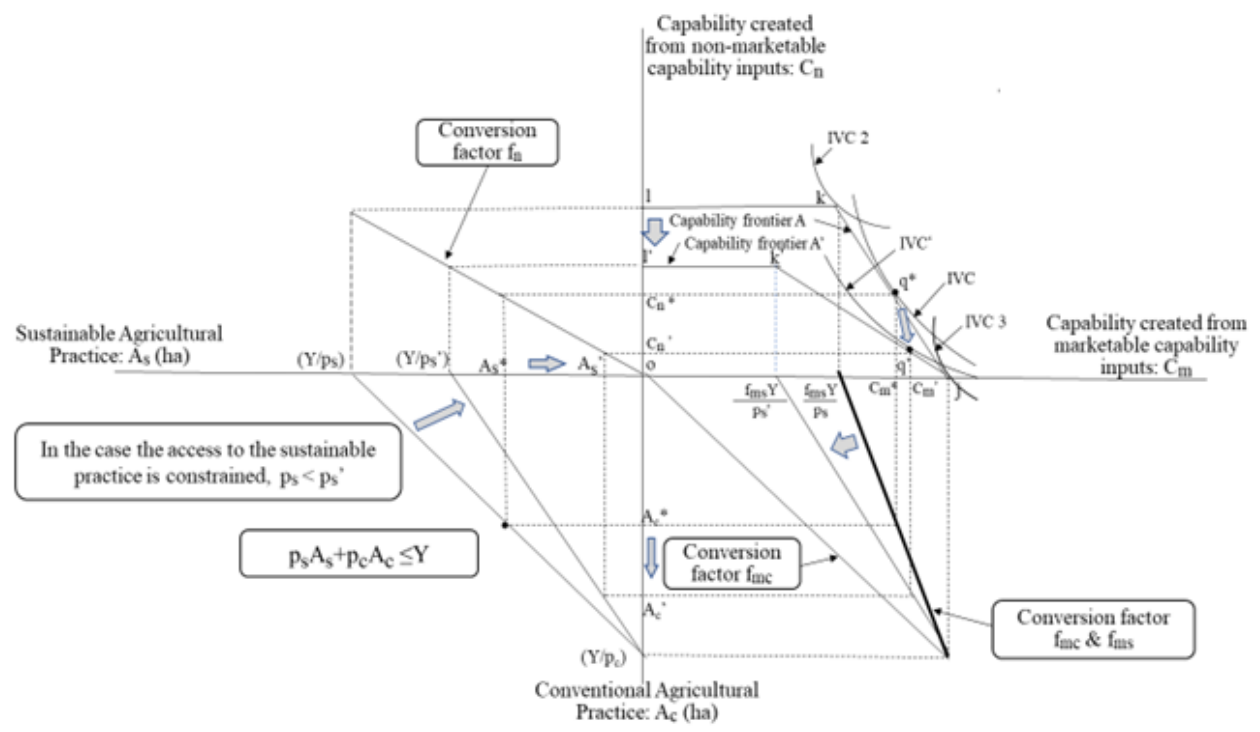

Notes: A farmer will maximise his or her capability value at $q^{*}$ of Figure 3 where the IVC and capability frontier (ojkl) meet each other (except corner solutions of IVC 2 or IVC 3 ). This case occurs when $\mathrm{S}$ in the equation is positive.

If $\mathrm{S}$ is negative, the capabilities from marketable capability inputs and non-marketable capability inputs are not in a trade-off relation, but rather, are complementary to each other (capability frontier A' shown as dotted lines in Figure 4). Thus, almost all the IVCs would meet with a capability frontier at the upper right corner $\left(\mathrm{q}^{\prime}\right)$. The economic dimension and the sustainable dimension are more easily aligned with each other than in the previous case. Farmers would expand the SAP to all areas of their farmland. If capability inputs from a SAP are efficiently produced and valued highly in the market, then well converted into functionings, this ideal case could unfold.

Figure 5 shows a case when the 'conversion factor' (Step 2) which transforms non-marketable capability inputs into capability is enhanced from $f_{n}$ to $f_{n}$ ' (e.g., improvement of farming skill to enhance biodiversity, a new community rule to promote aesthetic beauty of the farmland). This strengthened conversion factor results in expansion of a capability frontier, or well-being freedom, from ojkl to ojk'1' and could consequently raise the value of choice and expand the area of a SAP.

Figure 6 shows a case when a farmer changes his or her 'choice behaviour' (Step 3) in a way that puts more value on capability created from a SAP, which means that there is now a flatter indifference value curve. This might be caused by the farmer's autonomous deliberation based on personal agency derived from such accomplishments as his or her recognition of responsibility for the future or value for the ecosystem. The flatter $\mathrm{IVC}^{\prime}$ in Figure 6 meets his or her capability frontier at $\mathrm{q}^{\prime}$ instead of $\mathrm{q}^{*}$, the area of a SAP will be increased from $\mathrm{A}_{\mathrm{s}}{ }^{*}$ to $\mathrm{A}_{\mathrm{s}}{ }^{\prime}$ as a result. As Sen (2013) argues, if education or empowerment 
successfully transforms the value system of people in the community, it aids to affect people's behaviour and accumulatively enhances sustainability of the whole agricultural system without infringing on people's capability frontiers by coercion or constraint.

Figure 4 A case when capabilities from marketable and non-marketable capability inputs are complementary (dotted lines)

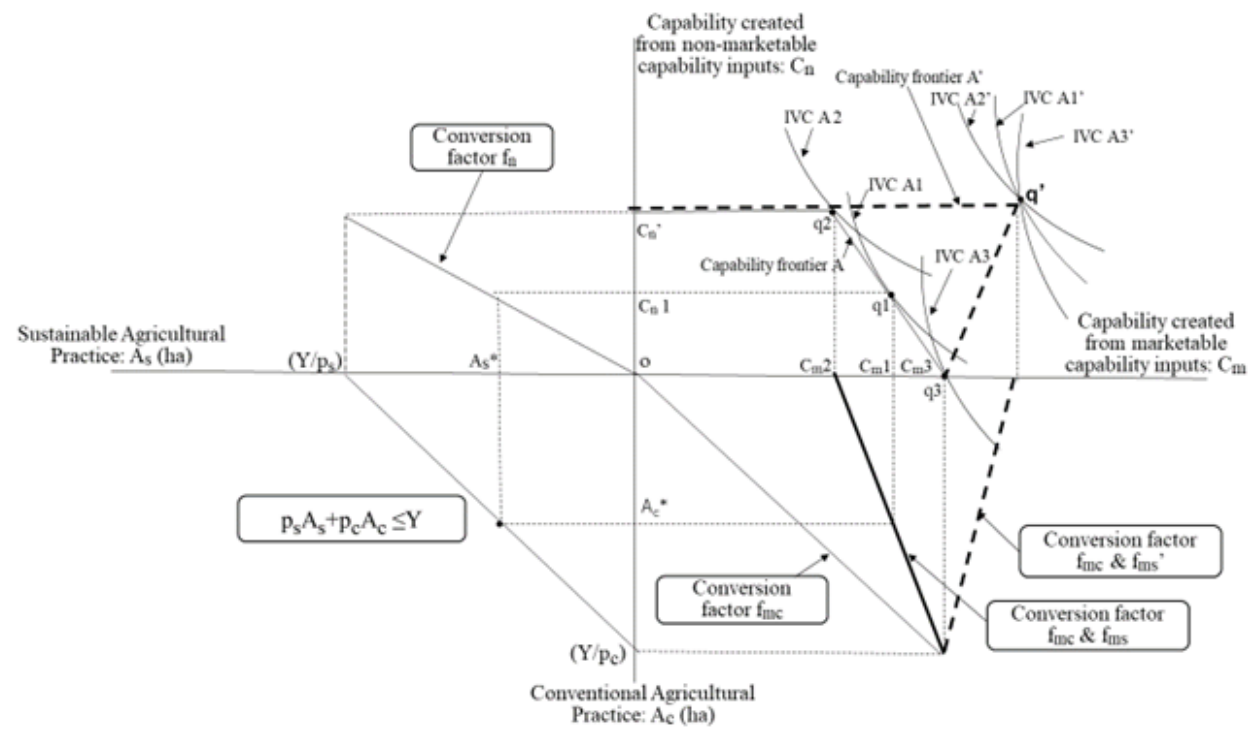

Notes: If $\mathrm{S}$ is negative, the capabilities from marketable capability inputs and non-marketable capability inputs are not in a trade-off relation, but rather, are complementary to each other (capability frontier $\mathrm{A}^{\prime}$ shown as dotted lines).

Almost all the IVCs would meet with a capability frontier at the upper right corner $\left(q^{\prime}\right)$.

Thus far, a focus has been mainly put on individual well-being. However, development of the agency aspect of freedom is equally important as depicted in the CA dynamic framework of Figure 2. Figure 7 shows an individual's choices will be accumulated producing effects on external environments, and at the same time, an individual's exertion of agency may accordingly facilitate deliberation in the community on issues concerning external environments, developing into collective agency actions which could consequently affect changes in social arrangements (Step 5). An example of such social changes is represented in Figure 7 as a higher cost for a CAP $\left(\mathrm{p}_{\mathrm{c}}{ }^{\prime}\right)$ (e.g., a new regulation on a CAP) and a lower cost for a SAP ( $\left.\mathrm{p}_{\mathrm{s}}{ }^{\prime}\right)$ (e.g., government support for dissemination of skills). In Figure 7, both constraint and promotion of capabilities are incorporated at the same time as social arrangements. As a result, although this farmer's value curve representing his or her sense of value is not changed, the choice could be shifted from $\mathrm{q}^{*}$ to $\mathrm{q}^{\prime}$ in accordance with a transformation of capability frontiers (from ojkl to oj' $\mathrm{k}^{\prime} \mathrm{l}^{\prime}$ ) to result in expansion of a SAP (from $\mathrm{A}_{\mathrm{s}}{ }^{*}$ to $\mathrm{A}_{\mathrm{s}}{ }^{\prime}$ ). 
Figure 5 A case when the conversion factor $f_{n}$ is enhanced to $f_{n}{ }^{\prime}$ (Step 2) (see online version for colours)

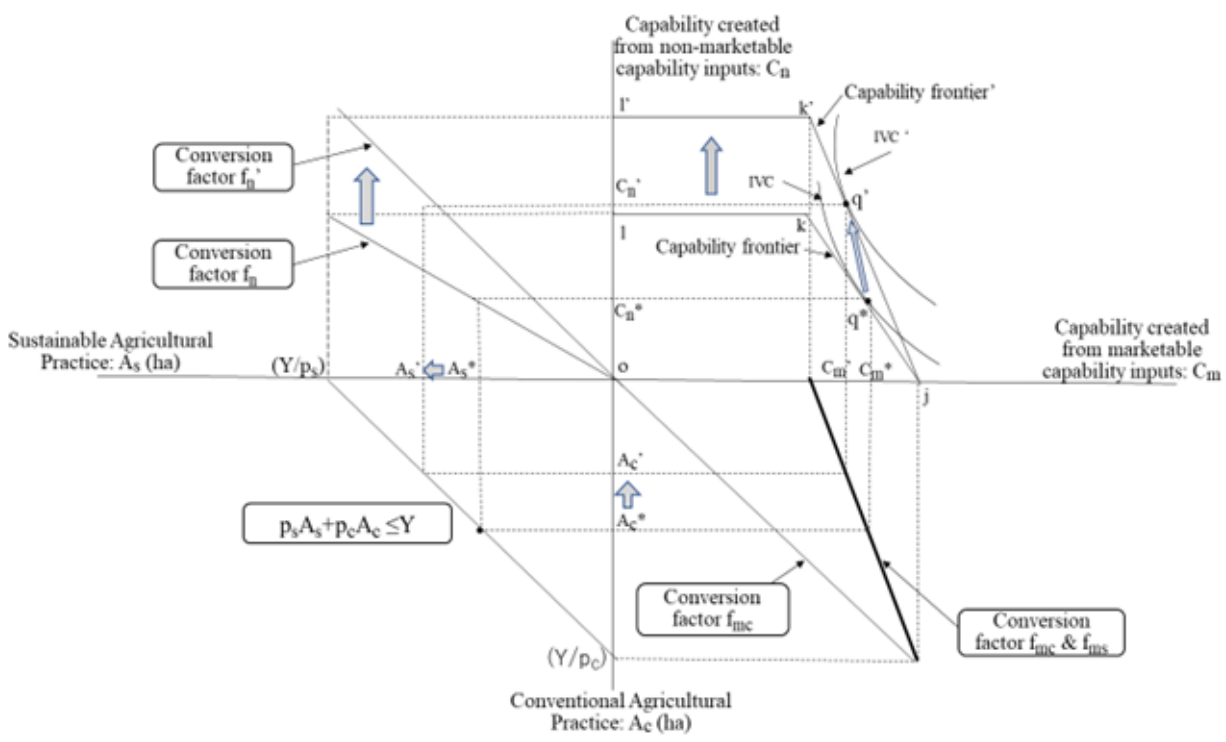

Notes: Figure 5 shows a case when the 'conversion factor' (Step 2) which transforms non-marketable capability inputs into capability is enhanced from $f_{n}$ to $f_{n}$ '. This strengthened conversion factor results in expansion of a capability frontier from ojkl to ojk' $\mathrm{l}^{\prime}$.

Figure 6 A case when a farmer's choice behaviour (IVC) changes (Step 3) (see online version for colours)

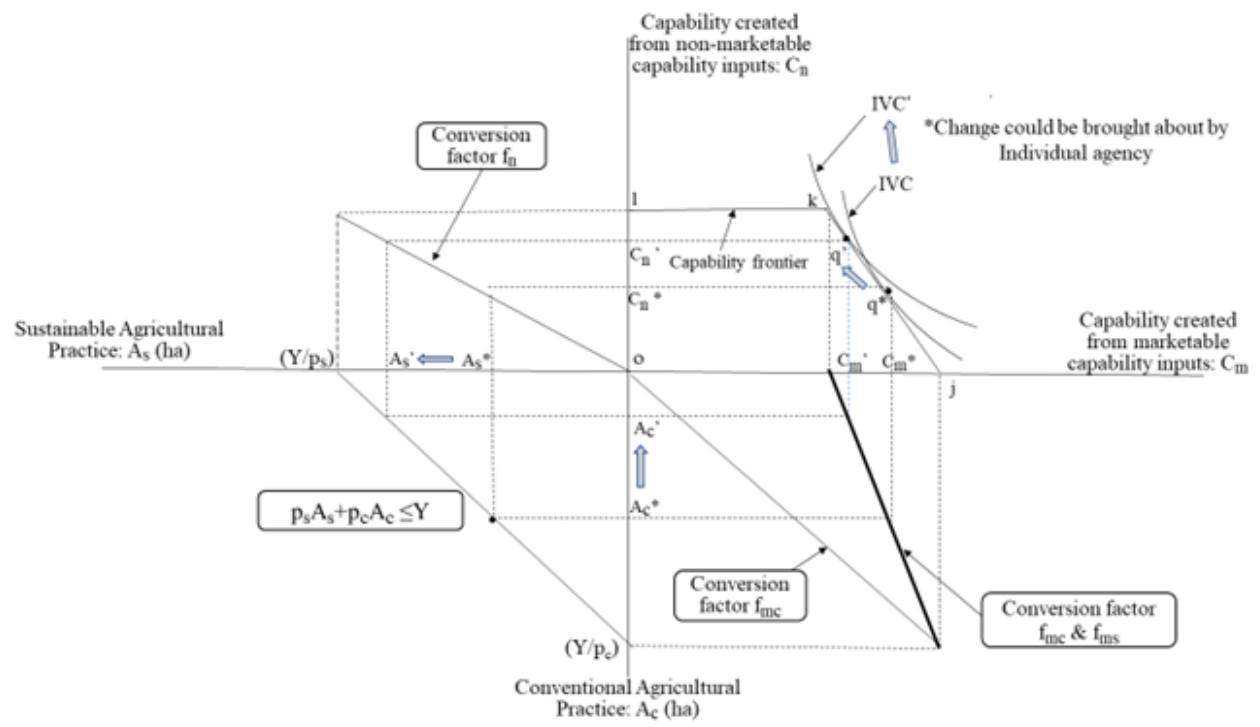

Note: Figure 6 shows a case when a farmer changes his or her 'choice behaviour' (Step 3) in a way that puts more value on capability created from a sustainable farming practice, which means that there is now a flatter indifference value curve. 
Figure 7 A case when collective agency affect changes in social arrangements (Steps 4 and 5) (see online version for colours)

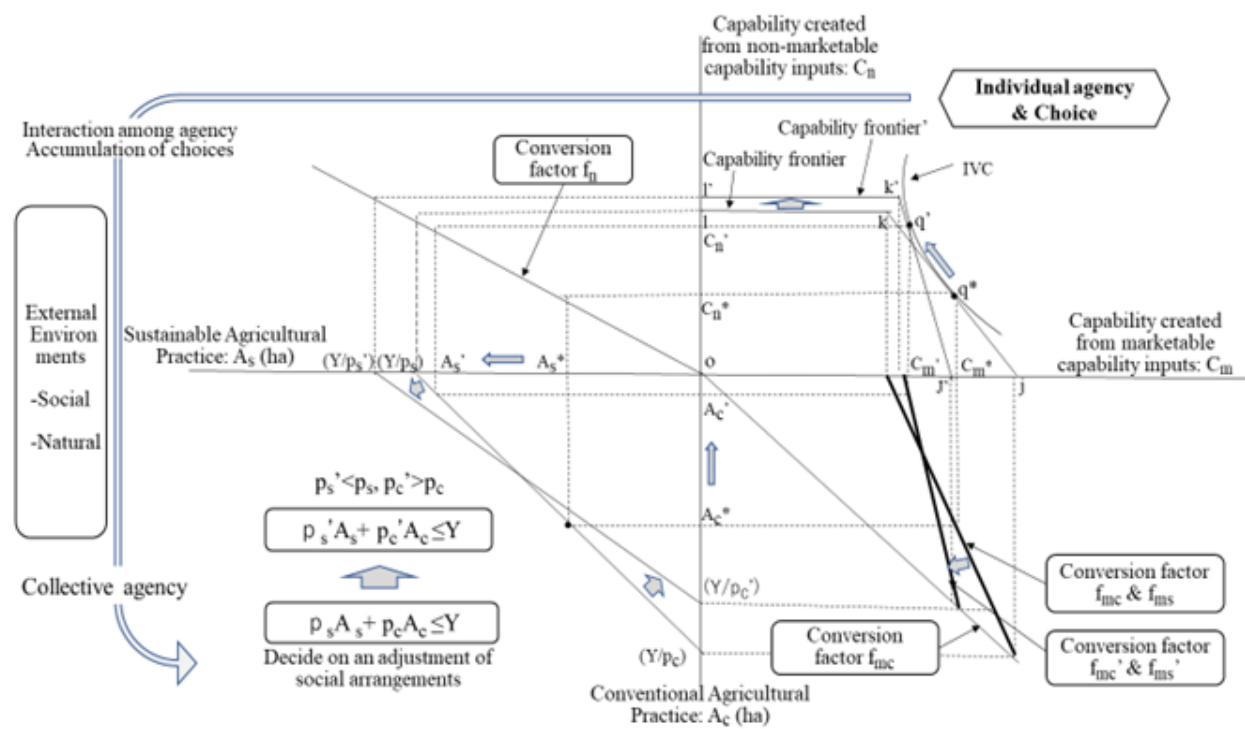

Note: Figure 7 shows an individual's choices will be accumulated producing effects on external environments, and at the same time, an individual's exertion of agency may accordingly facilitate deliberation in the community on issues concerning external environments (Step 4), developing into collective agency actions which could consequently affect changes in social arrangements (Step 5).

As investigated in this section, the CA dynamic framework may be useful in identifying and analysing what farmers engaging in a SAP would value, what would be constraints or promoters in their creating capabilities, and how the mechanism of their choice behaviour would work. Also, it may aid to identify possible measures, which would affect variables such as $p_{s}, p_{c}, f_{n}, f_{m s}$ as well as the formation of values among farmers, by closely investigating each phase of the issue based on the CA dynamic framework.

\section{The case of Sado ASW}

In this section, the relationship between Sado ASW and the capabilities of farmers working and living there are analysed with the CA dynamic framework. Sado is an island located off the coast of Niigata prefecture of Japan. For centuries, Sado ASW has been transformed through the interplay between human society, economic activities and the natural environment. Recently, the community of Sado was commercially successful by establishing its brand of agricultural products, such as rice and fruits. However, at the beginning of this century, its rice production was heavily damaged by bad weather in two consecutive years. Then, the area started to explore a different type of agriculture. During the last decade, it has been making efforts to shift from a CAP to a more sustainable one which aims at co-existence with nature, especially with the Japanese crested ibis (Nipponia nippon), once extinct in the country and reintroduced in Sado recently. 


\subsection{The Japanese crested ibis and Sado Island}

According to Ishii et al. (1994), the Japanese crested ibis was once widely distributed across Asia including Japan, Korea, China and Siberia. However, this species started to disappear over its entire range in the late 19th or early 20th century (Ishii et al., 1994). In Japan, Japanese crested ibis population started to decrease in the late 19th century because of overhunting for its feathers and considerable changes to its habitat caused by development and changes in agricultural practices. Their number dwindled and became extinct in 2003. The government started its plan to reintroduce this species to Sado through captive breeding. In 2008, ten Japanese crested ibis were reintroduced to Sado for the first time. Until now (March 2020), 364 Japanese crested ibis have been released, of which 166 are alive. In addition, there are now 234 Japanese crested ibis that have fledged in the wild and are alive today (MOE Reintroduction Center, 2008).

\subsection{Relationship between the ASW in Sado and its ecosystem, and the reintroduction of the Japanese crested ibis}

Rice paddy fields, some situated in the middle of the island and others surrounded by orchards and forestry, used to be main foraging habitats for the Japanese crested ibis in Sado because of the abundance of animal species such as loaches, frogs and insects. After significant changes in the surrounding environment, recently - under close collaboration among farmers, NGOs, and governments - a specific SAP has been introduced and implemented for the conservation of the ecosystem and the ibis's foraging habitats. In 2008, Sado city government started a program to promote the new agricultural practice under the slogan 'Create village living with the Japanese crested ibis' and to certify 'rice' produced under the following conditions:

1 Reduction of the use of agricultural chemicals (pesticide and fertilises) to less than $50 \%$ of conventional farming practices.

2 Adoption of one of the following sustainable cultivation techniques for fostering biodiversity:

a winter-flooding of rice paddy fields

b installation of the traditional ditch called ' $e$ ' as refuge for aquatic species

c installation of fish passes connecting rice paddy fields to drainage canals

d installation of aquatic biotopes connected to rice paddy fields by canals

e organic production.

3 Implementation of biodiversity surveys twice a year.

4 No application of herbicide on ridges alongside the rice paddy fields.

\subsection{Observation of capabilities of farmers and other stakeholders based on the CA dynamic framework}

For this analysis, semi-structured interviews were conducted in May and June 2018 with subjects recruited via original interviewees in a respondent driven manner (some were added in July 2019). The interviewees include farmers and other stakeholders: Sado citizens, NPO members, agricultural organisation officials, people from research and 
education centres, government officials and politicians. The total number of interviewees was 29 (Table 1). Basic questions are as follows:

1 What do you think the collaborative activities of the Sado SAP for conservation of the ecosystem brought to your life?

2 What do you think the reintroduction of the Japanese crested ibis brought to your life?

3 How are you involved in the collaborative activities related to the Sado SAP?

4 What are challenges in continuing the activities?

5 What do you expect from other stakeholders for the Sado SAP?

Some supplementary question items were also added during the interviews in response to what the interviewees said. Duration of each interview was from 45 to 60 minutes and the content of interview was noted with the consent from interviewees (Table 2).

\subsection{Interview results about enhancement of capability, well-being freedom}

Firstly, based on the interview items 1, 2 and 3, the relationship between the Sado SAP and the generation of 'capabilities' is investigated (Table 3). Farmers commonly described that they welcome the Japanese crested ibis around their rice paddies with 'joy' and 'satisfaction' and often 'feel pride in doing good to the ecosystem and landscape'; older farmers noted they are rediscovering the wonderfulness of working in nature. Rangers of the Ministry of Environment mentioned that during the field surveys, more ibis are identified in the paddies under the Sado SAP than in other paddies. Farmers, NPO members and government officials agreed that the effects on environmental improvement differ by the level of farmers' skill and the types of sustainable cultivation techniques.

Farmers and officials from the government and agricultural organisations said that because of the rice certification system, farmers could "sell their products at a higher price than the rice from a conventional practice." However, several farmers described that older farmers without a connection with buyers have to count on the agriculture cooperative.

Farmers, citizens, members of NPOs, government officials and politicians showed expectations for eco-tourism based on achievements of the Sado SAP (e.g., farm products, ibis, landscape), but stated that it is not yet successful as a business. However, politicians showed appreciation for economic opportunities and regional activation brought about by the Sado SAP.

Farmers and a schoolteacher described that the Sado SAP presented 'occasions and spaces' to learn with children and citizens in the community and all enjoyed such activities for themselves. Farmers and citizens mentioned that engaging biodiversity surveys with an NPO allowed them to learn of the interaction between their activities and the ecosystem and helped to improve the agricultural practices. Some farmers showed desire to advance their sustainable cultivation techniques to organic farming or another method which refrains from inputs by optimising the use of soil fertility. Moreover, interviewees involved in research explained that the activities provided 'spaces to study and discuss closely with local residents' on how to explore 'a social system coexistent with nature'. Farmers, citizens and teachers noted that people who had participated in the 
activities seem to have strengthened their attachment to the nature of the island where they live and 'their emotional connection with Sado'.

Table 1 List of interviewees

\begin{tabular}{|c|c|c|c|c|}
\hline Interviewees - farmers & $J o b$ & Age & Sex & Location \\
\hline 1 & $\mathrm{~F}$ & $50^{\prime}$ & M & Niibo \\
\hline 2 & $\mathrm{~F}$ & $50^{\prime}$ & M & Niibo \\
\hline 3 & $\mathrm{~F}$ & $60^{\prime}$ & M & Ryoutsu \\
\hline 4 & $\mathrm{~F}$ & $60^{\prime}$ & M & Ryoutsu \\
\hline 5 & $\mathrm{~F}$ & $70^{\prime}$ & M & Hatano \\
\hline 6 & $\mathrm{~F}$ & $70^{\prime}$ & M & Ryoutsu \\
\hline 7 & $\mathrm{~F}$ & $70^{\prime}$ & M & Ryoutsu \\
\hline 8 & $\mathrm{~F}$ & $70^{\prime}$ & M & Niibo \\
\hline 9 & $\mathrm{~F}, \mathrm{NP}$ & $30^{\prime}$ & M & Niibo \\
\hline 10 & $\mathrm{~F}, \mathrm{CG}$ & $40^{\prime}$ & $\mathrm{M}$ & Ryoutsu \\
\hline 11 & $\mathrm{~F}, \mathrm{CG}$ & $40^{\prime}$ & $\mathrm{M}$ & Sawada \\
\hline 12 & $\mathrm{~F}, \mathrm{CG}$ & $50^{\prime}$ & $\mathrm{M}$ & Aikawa \\
\hline 13 & $\mathrm{~F}, \mathrm{PO}$ & $60^{\prime}$ & M & Kanai \\
\hline Interviewees - non-farmers & \multicolumn{2}{|c|}{$J o b$} & \multicolumn{2}{|c|}{$\operatorname{Sex}$} \\
\hline 1 & \multicolumn{2}{|c|}{ NP } & \multicolumn{2}{|c|}{$\mathrm{F}$} \\
\hline 2 & \multicolumn{2}{|c|}{$\mathrm{CG}$} & \multicolumn{2}{|c|}{ M } \\
\hline 3 & \multicolumn{2}{|c|}{$\mathrm{CG}$} & \multicolumn{2}{|c|}{ M } \\
\hline 4 & \multicolumn{2}{|c|}{ PG } & \multicolumn{2}{|c|}{ M } \\
\hline 5 & \multicolumn{2}{|c|}{ NG } & \multicolumn{2}{|c|}{ M } \\
\hline 6 & \multicolumn{2}{|c|}{ NG } & \multicolumn{2}{|c|}{ M } \\
\hline 7 & \multicolumn{2}{|c|}{ PO } & \multicolumn{2}{|c|}{ M } \\
\hline 8 & \multicolumn{2}{|c|}{$\mathrm{PO}$} & \multicolumn{2}{|c|}{ M } \\
\hline 9 & \multicolumn{2}{|c|}{$\mathrm{AC}$ (university) } & \multicolumn{2}{|c|}{$\mathrm{F}$} \\
\hline 10 & \multicolumn{2}{|c|}{$\mathrm{AC}$ (university) } & \multicolumn{2}{|c|}{ M } \\
\hline 11 & \multicolumn{2}{|c|}{ AC (high school) } & \multicolumn{2}{|c|}{ M } \\
\hline 12 & \multicolumn{2}{|c|}{$\mathrm{ST}$} & \multicolumn{2}{|c|}{ M } \\
\hline 13 & \multicolumn{2}{|c|}{$\mathrm{AO}$} & \multicolumn{2}{|c|}{ M } \\
\hline 14 & \multicolumn{2}{|c|}{$\mathrm{AO}$} & \multicolumn{2}{|c|}{ M } \\
\hline 15 & \multicolumn{2}{|c|}{$\mathrm{CT}$} & & \\
\hline 16 & & & & \\
\hline
\end{tabular}

Note: F: farmer (including part time), NP: NPO official, CG: city government official, PG: prefectural government official, NG: national government official (Ministry of Environment), PO: politician, AC: academic, ST: student, AO: agricultural organisation official and $\mathrm{CT}$ : citizen. 
Table 2 Summary of statements

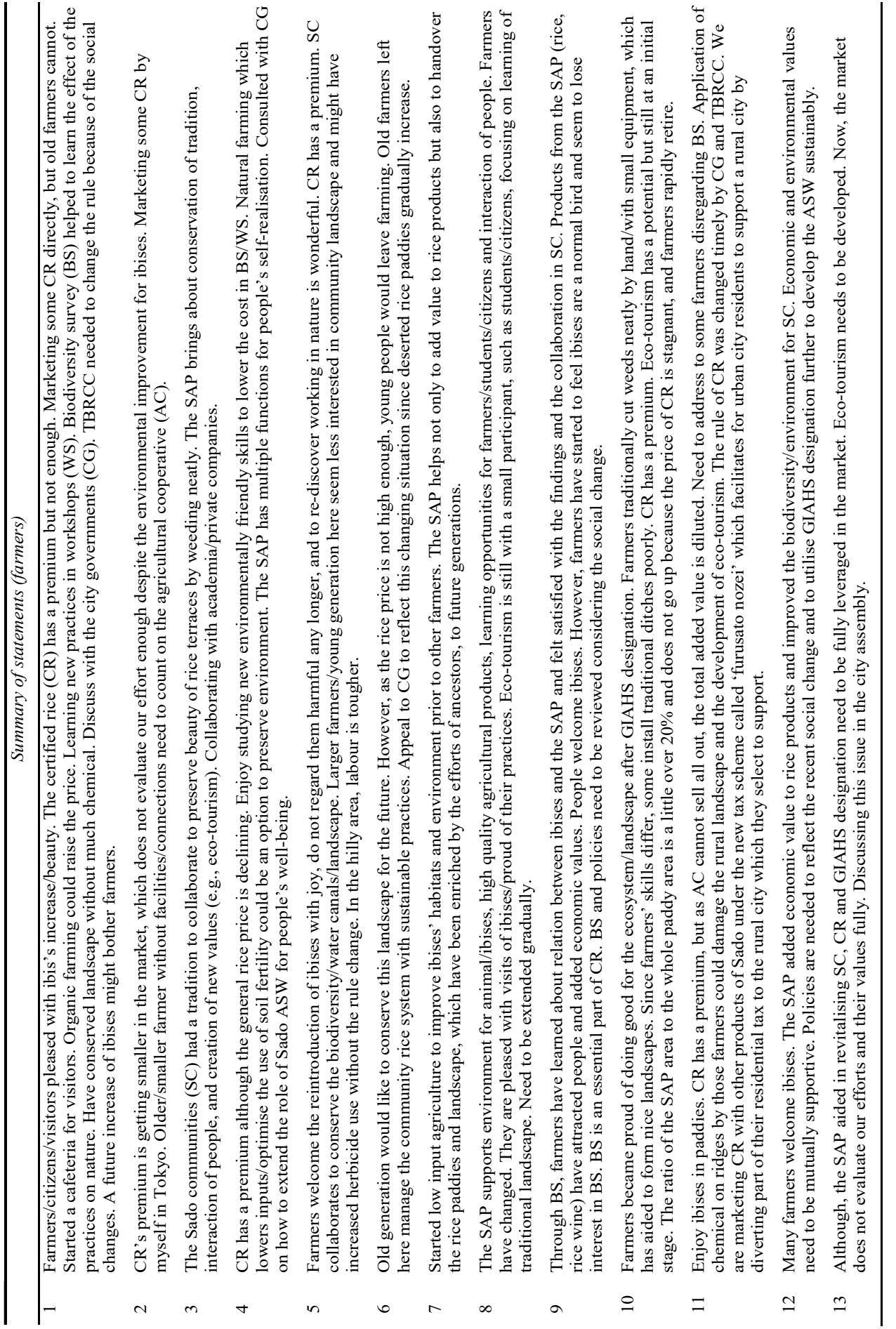


Table 2 Summary of statements (continued)

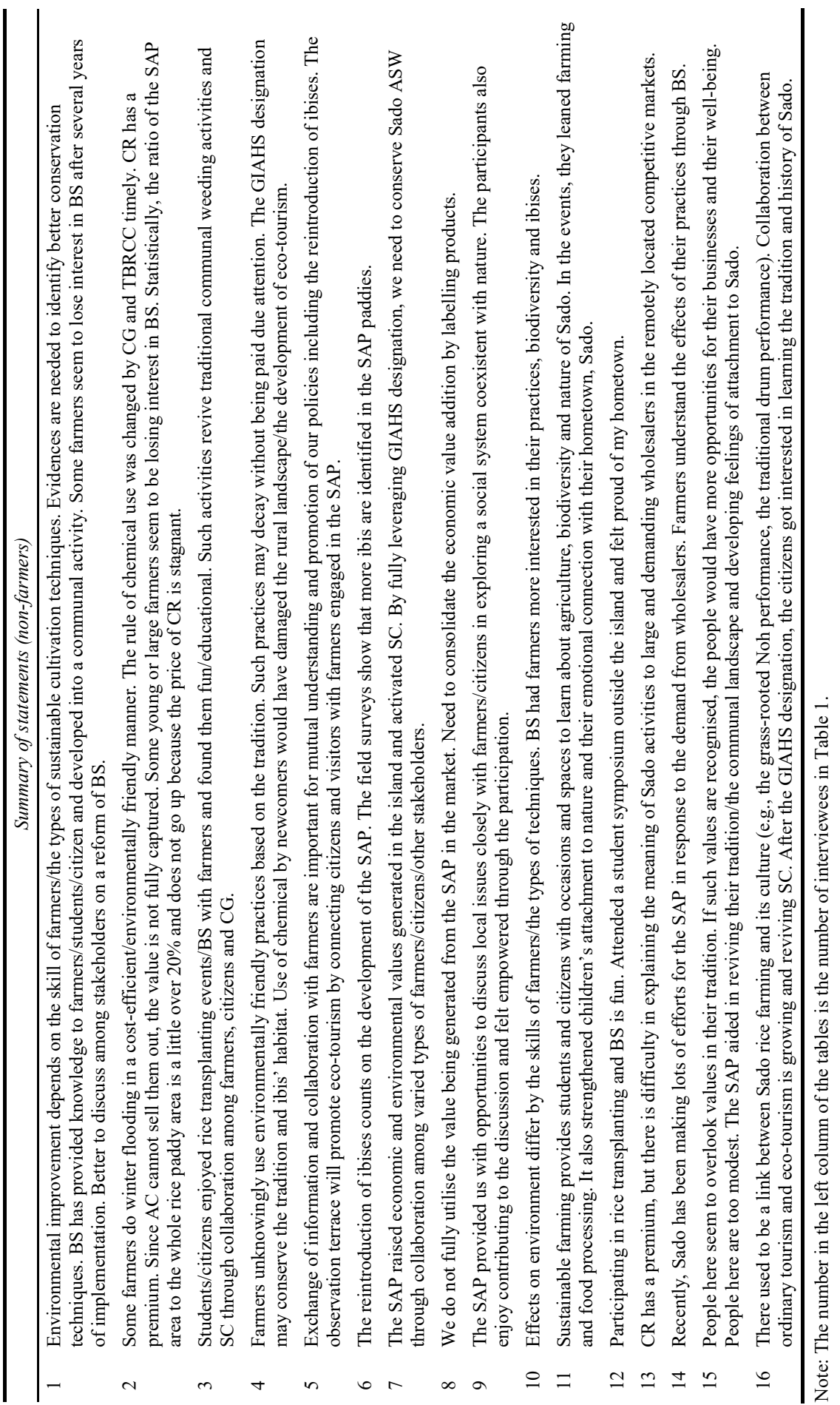


Table 3 Capability inputs, functionings and agency actions identified in the interviews

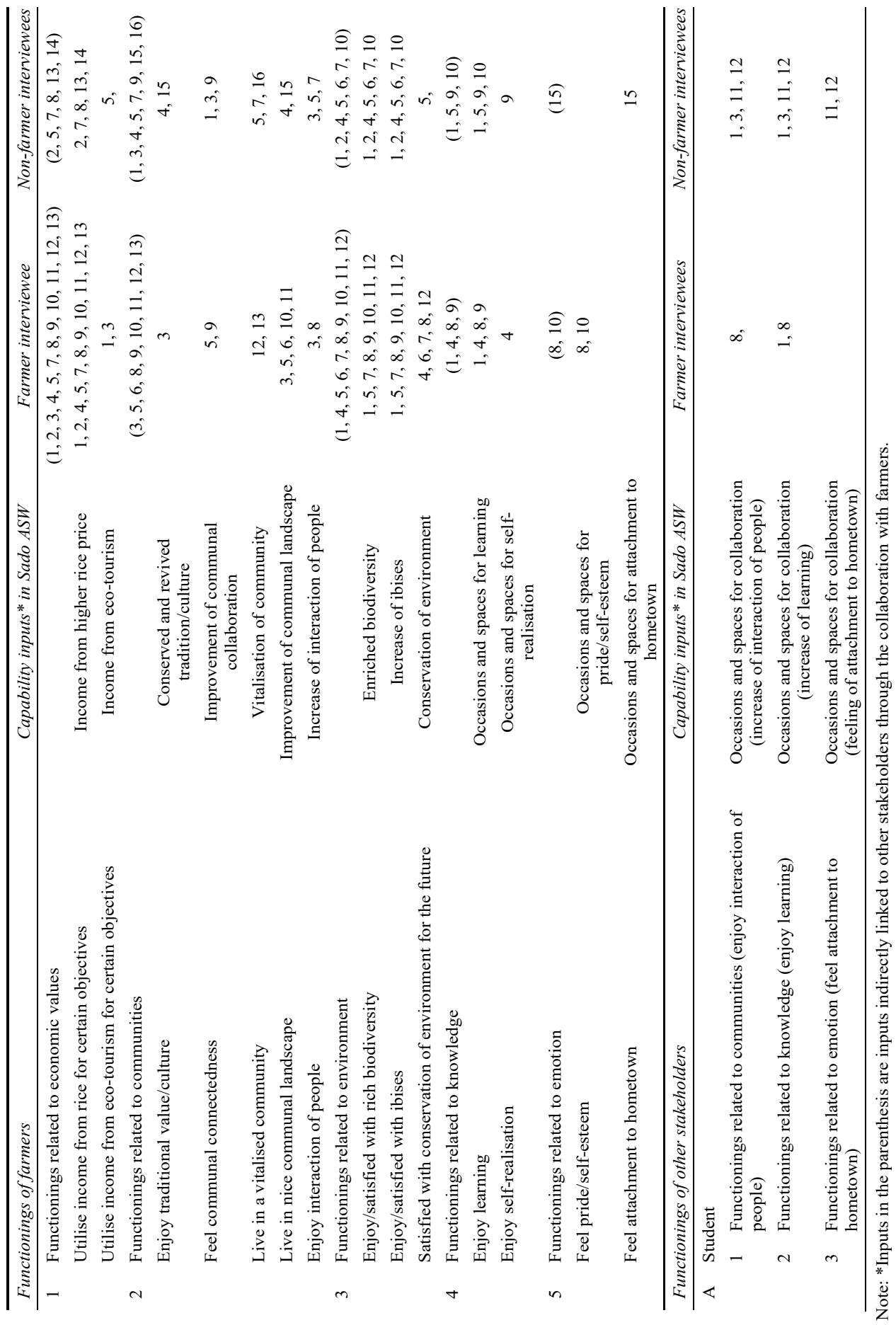


Table 3 Capability inputs, functionings and agency actions identified in the interviews (continued)

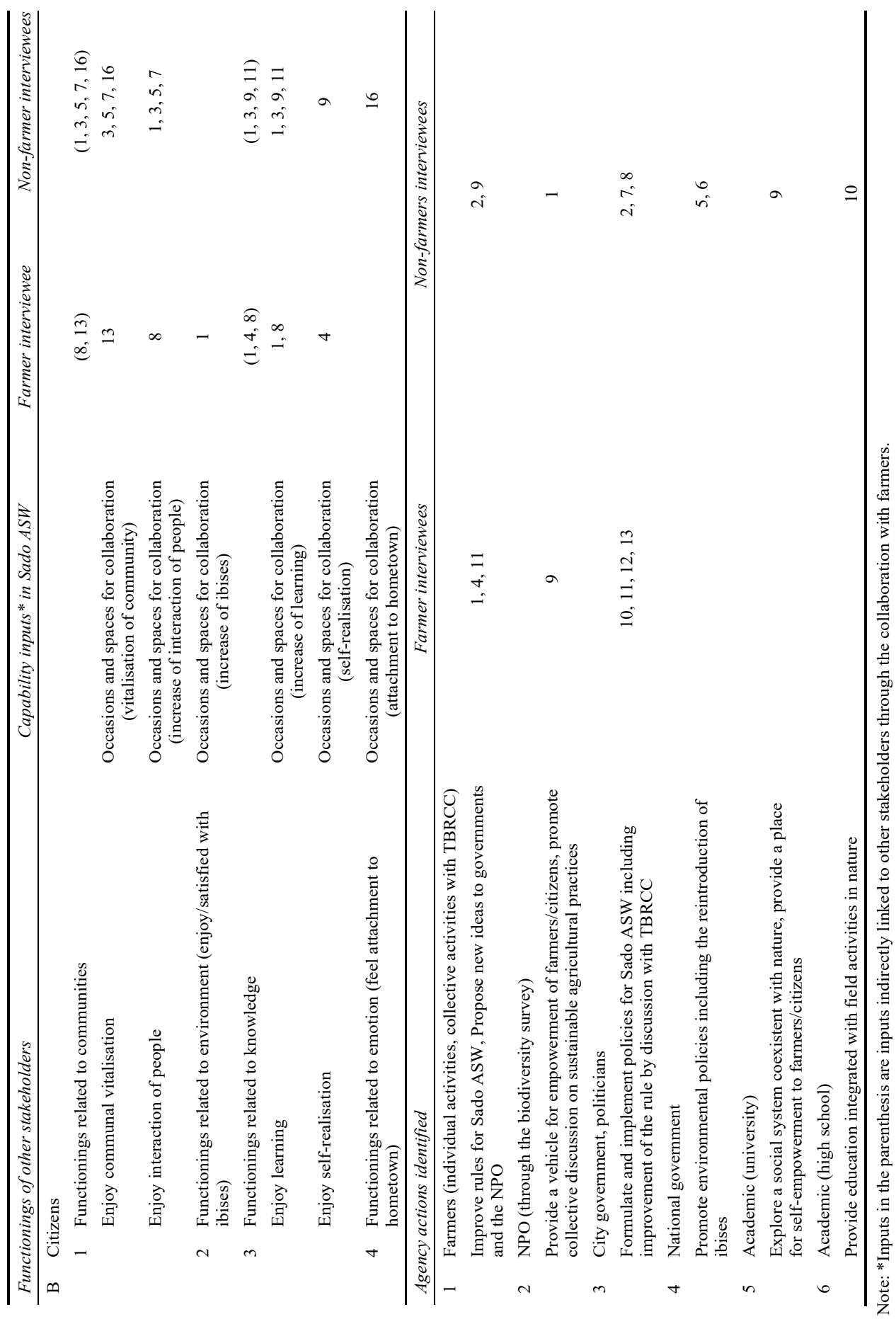


Not all feedback was positive, however. In the interviews related to items 3, 4 and 5, some farmers, officials from the government, and NPO members showed concerns that some farmers, such as relatively young newcomers, start losing interest in the biodiversity survey. They also said that policies would need to reflect the situation of an aging community.

Farmers, government officials and politicians stated that markets do not evaluate the community's efforts fairly enough. Officials from agricultural cooperatives described a difficulty in conveying the meaning of the activities of the community to consumers living in remote areas. Officials from the government said the number of farmer participants and the total area of the Sado SAP started to gradually decline recently, and the ratio of the area to the whole rice paddy area is a little over $20 \%$ and does not go up because the price level of the certified rice is stagnant, while the farmers' retirement increases in the rapidly aging community. Yet, they did mention that the city government started marketing the certified rice with other products of Sado under the new tax related scheme which facilitates for urban city residents to support a rural city by diverting part of their residential tax to the rural city government, and at the same time, promotes their consumption of products from the rural city.

\subsection{Interview results on a new requirement for the certification of the Sado SAP}

Many interviewees felt it was important to discuss a new requirement for certification of the Sado SAP. Among the conditions for Sado certified rice, there is one condition which requires "no application of herbicide on ridges alongside the rice paddy fields." This requirement was not in the original rule but added later in 2017. Officials of the government described that "People in Sado traditionally cut weeds on ridges neatly by hand or with a small piece of equipment, which has aided to form a nice rural landscape on the island." Recently though, farmers became concerned with a "possible increase in the application of herbicide on ridges by large scale farmers and young farmers" and that such a change in behaviour could accumulate to alter the whole landscape of the island. Some interviewees emphasised a concern for 'rural aesthetic beauty', others for 'damages to the development of eco-tourism'. In addition, they learned from communicating with academics that "the ridges are regarded as very important foraging habitats for ibis during the summertime" (Endo and Nagata, 2013). This issue was discussed by a non-profit organisation called Toki Brand Rice Certification Council (TBRCC). TBRCC was established by farmers producing the certified rice, officials from the city government and agricultural cooperatives, and NGOs to discuss and deliberate various issues in order to promote the SAP in Sado. The earnest discussion in TBRCC led stakeholders to reach an agreement on this matter.

\section{Discussion}

With regard to farmer participants, the Sado SAP seems to have enhanced their capabilities. As achieved functionings, they generally gained satisfaction by living life alongside nature and the ibis; their contribution to the improvement of the environment and experiencing a unique socio-economic-natural interaction with other community members was also beneficial. If the marketable capability input, such as incomes from the certified rice, was not enough for producing some of their functionings without 
feeling constraints, as several farmers suggested, the current situation of the Sado SAP might be represented more closely by Figure 3 than by Figure 4, then also, the capability from non-marketable capability inputs might help to uphold a balance of the choice in favour of the SAP.

The NPO - acting as an agent which empowers farmers regularly through the biodiversity survey on the field - seems not only to help farmers create a technical base of capability to use the occasion of farming for improvement of the environment and the ibis's habitat as shown in Figure 5 (higher $\mathrm{f}_{\mathrm{n}}$ ) but also seems to have an effect on farmers' value systems which affect their choice behaviour about the types of agricultural practices available to them, like Figure 6 depicts. The activities of the NPO work favourably for the promotion of the SAP in the community and might be regarded as a base for collective agency.

In relation to the new requirement on the prohibition of herbicide use in ridges, the recognition of the possible negative impact on the ecosystem and landscape by herbicide use prompted people's agency within this context. The sharing of new knowledge aids to involve a wide range of stakeholders in collective deliberation. TBRCC seemed to play a role as a base for collective agency in this process. This resulted in an amendment of the requirements in the certification rule in 2017. The amendment worked as a substitute of a traditional rule, which has conserved the weeding practice of farmers, the ecosystem, and the ibis's forage habitat for many years, but these have recently been declining with the social structural changes.

However, if the current situation of the Sado SAP is represented as in Figure 3, this will mean that, by promoting the SAP, farmers are facing a trade-off between two different types of capabilities, one created from marketable capability inputs and the other from non-marketable capability inputs. If the added value for the certified rice further declines, as some farmers are concerned about, it will make the capability frontier recede, a total value of choice reduce, and the total farmland area for a SAP could be seen reduced as well.

In addition, from the interviews, the conversion factors and value systems among the community members seem to be diversified. Market-oriented farmers have a relatively more stable conversion factor, $f_{m s}$, and the effect of the change may not affect their conversion factor. On the other hand, as suggested in the interviews and the previous study [Oda and Kiminami, (2014), p.90], if older farmers are to possess 'relatively higher' environmental consciousness than younger ones, the IVCs of older farmers would be flatter, and thus, they might be able to stay in a position favourable to the sustainable practice in the occasion of a price change. It seemed necessary for the social arrangements of the communities to be re-examined for continuous collaboration among stakeholders aiming for the sustainable management of Sado ASW.

We can compare these different positions among farmers with a graph by classifying the farmers into three groups: one with high marketing skill (Group 1), one with high environmental consciousness (Group 2), and other farmers (Group 3). We will assume the three groups are in the same conditions except for conversion factor $\left(f_{m s}\right)$ and their IVC slopes as described in Figure 8. After a price change occurs, while the conversion factors of Group 2 and Group 3 decline from $f_{m s}$ to $f_{m s}$, Group 1 keeps the same $f_{m s}$, and Group 2 keeps relatively higher valuation on the sustainable practice in their IVCs. As a result, Group 1 may stay at $\mathrm{q} 1 *$, while Group 2 may shift from q2* to q2', and Group 3 may shift from q3* to $\mathrm{q}^{\prime}$, possibly reducing their SAP in its totality. As a result, the management of the whole watershed through the SAP would be degraded. 
Figure 8 Changes of capabilities of three groups of farmers (see online version for colours)

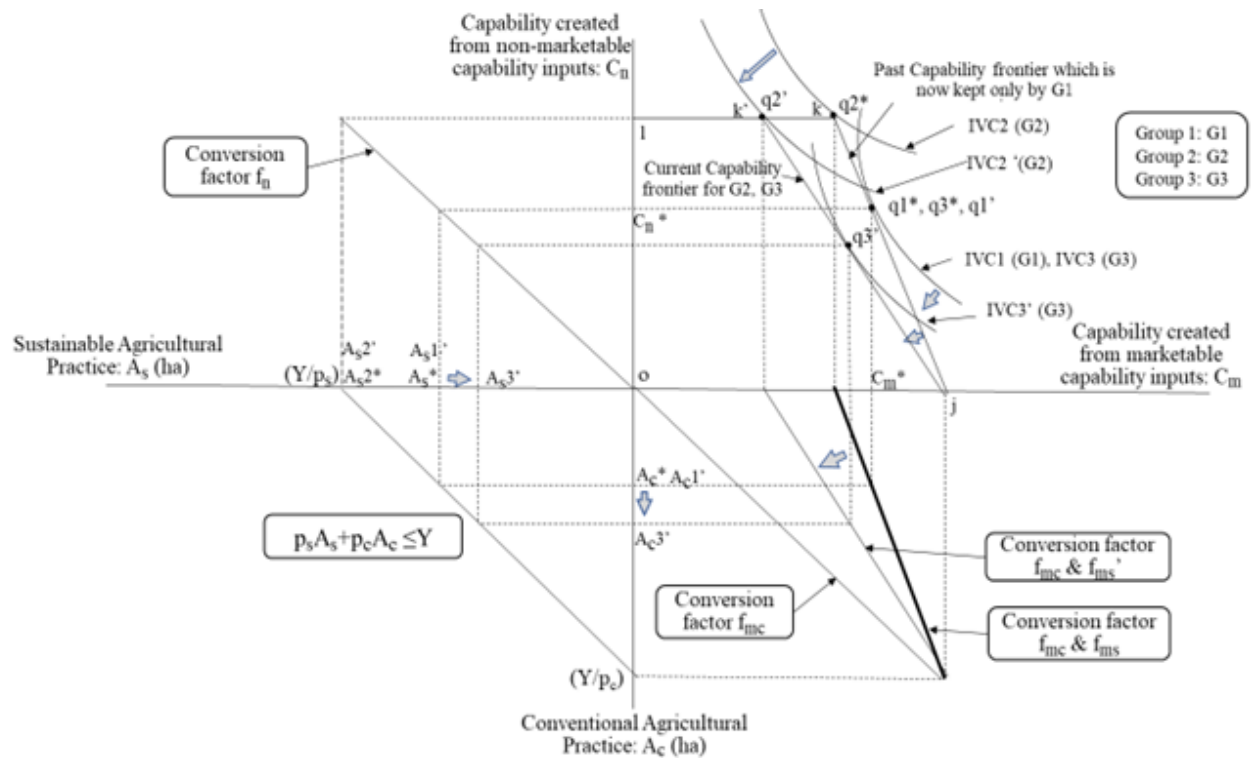

Note: After a price change occurs, while the conversion factors of Group 2 and Group 3 decline from $\mathrm{f}_{\mathrm{ms}}$ to $\mathrm{fms}_{\mathrm{m}}$, Group 1 keeps the same $\mathrm{f}_{\mathrm{ms}}$, and Group 2 keeps relatively higher valuation on the sustainable practice in their IVCs.

Thus, it would be necessary for farmers and other stakeholders together as a community, to deliberate on a rearrangement for a fair and sustainable management system of Sado ASW to counteract against a possible change in the market. Deliberation among stakeholders about 'socially desirable changes of capability frontiers' for the three groups in different positions would facilitate reaching an agreement for the fair and sustainable management of Sado ASW. Then, the type of intervention which is needed to induce the deliberated changes of capability frontiers could be developed. After that, the changes of capability through the intervention would redirect the groups to favour the sustainable management of Sado ASW.

From the interviews, in relation to capability creation, it may be fair for stakeholders to discuss an option which would not disturb market-oriented farmers, Group 1, who have already created relatively broader capability frontiers through their efforts to address a certain change, and which would not put too much moral burden for conserving the ASW on Group 2, although the commitment based on their value systems is the essential motor for the community to broaden the sustainable practice. Also, it would be a better option to revitalise Group 3 to enable them to bear commensurate roles in the collaborative sustainable practice in the aging community.

To help achieve this, there were suggestions from the interviews which seem to be worth deliberating upon within the community. Firstly, focusing on new sustainable practices started by some farmers could be an option. Facilitating access to such new methods could synergistically expand farming skills to achieve an improvement in the environment (higher $\mathrm{f}_{\mathrm{n}}$ ); then farmers, especially in Group 2, might evaluate such a personal additional contribution with higher satisfaction (keeping flat IVC). Secondly, another possible option would be the use of the new tax conversion system as a tool to 
market to large city consumers. It would make it easier for small farmers with weak market connections to differentiate their products since they could portray their unique sustainable practice through a public advertising channel such as a city government's homepage, to consumers with a high level of awareness on social and environmental issues. It might bring economic benefits not only to the certified rice for Group 2 and Group 3 but also to the eco-tourism under planning in the community (higher $\mathrm{f}_{\mathrm{ms}}$ ). Through these two changes, as Figure 9 shows, the capability frontier expands (dotted lines) to alleviate the situation of Group 2 and Group 3 by enhancing their capability choice (q2* $\left.\rightarrow \mathrm{q} 2^{\prime} \rightarrow \mathrm{q} 2^{\prime \prime}, \mathrm{q} 3^{*} \rightarrow \mathrm{q} 3^{\prime} \rightarrow \mathrm{q} 3^{\prime \prime}\right)$ to extend the SAP, while not disturbing the present capability of Group 1 significantly.

Figure 9 Planning an expansion of capability frontiers for Group 2 and Group 3 through an intervention

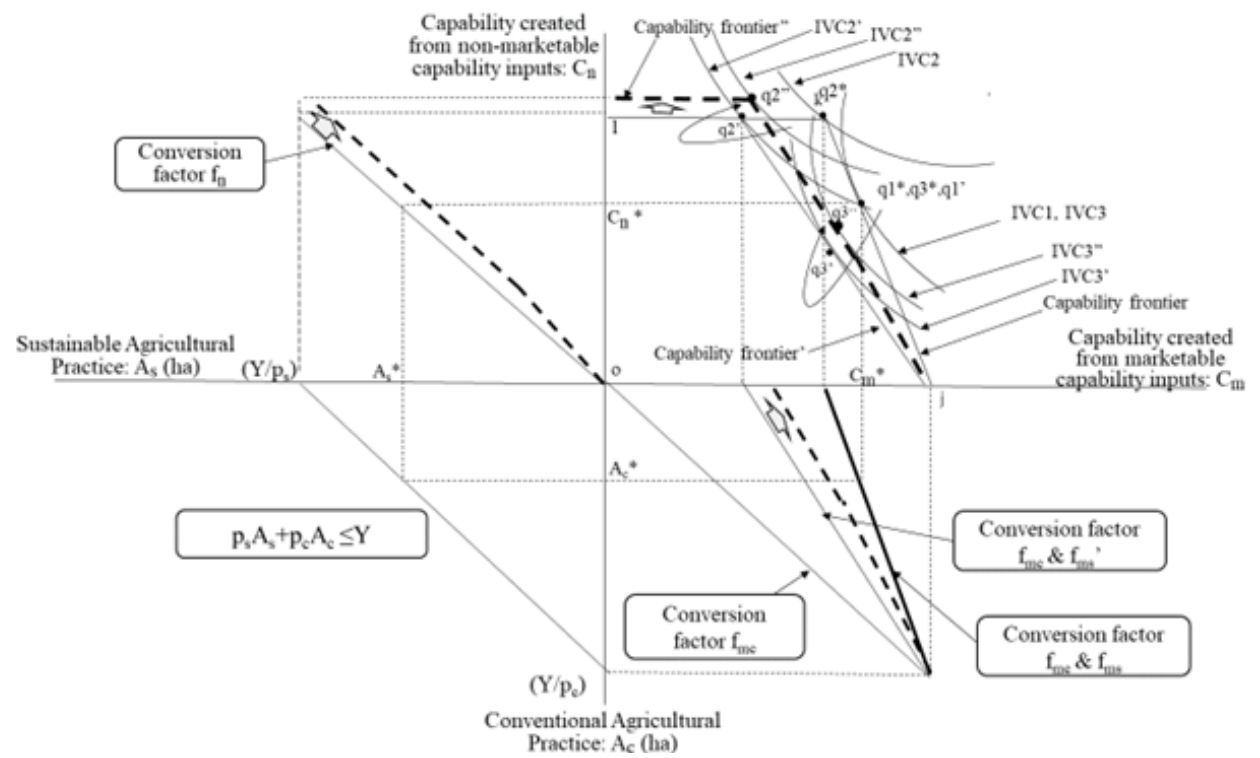

Note: Through these two changes, as Figure 9 shows, the capability frontier expands (dotted lines) to alleviate the situation of Group 2 and Group 3 by enhancing their capability choice (q2* $\left.\rightarrow \mathrm{q} 2^{\prime} \rightarrow \mathrm{q} 2^{\prime \prime}, \mathrm{q} 3^{*} \rightarrow \mathrm{q}^{\prime} \rightarrow \mathrm{q} 3^{\prime \prime}\right)$ to extend the SAP, while not disturbing the present capability of Group 1 significantly.

As discussed in this section, the analysis of the CA allows us to investigate the different status of capabilities and choice behaviour among farmers. The stakeholders' participatory deliberation as agents is important to judge priority and fairness among people in different positions. The CA aids to examine and prepare a plan of necessary interventions for this deliberation to promote the sustainable management of ASWs.

However, the models used in this paper are very much simplified. Real conversion factors would be far more complicated. Each functioning or capability is not so easily quantified. Some functionings from non-marketable capability inputs could be in a trade-off relation with each other. For instance, the increasing number of ibis might create aversions among farmers as a harmful animal just like old days. Thus, a more detailed analysis on different types of functionings in varying contexts will be needed. 
Also, thematic knowledges from ecology, agronomy, sociology and economics will help to advance the analysis of sustainable development based on the CA dynamic framework.

\section{Conclusions}

An ASW, such as a rice paddy system, can play multiple roles in enhancing the quality of human life. In the analysis of the relationship between an agricultural system and quality of human life, socio-economic-environmental contexts play extremely important roles. The CA analyses human development with emphasis on equity among people by using two aspects of freedom, that is 'well-being freedom' and 'agency freedom'. In this paper, we have discussed that this approach will assist to analyse the two streams of processes in which an ASW develops to sustainably enhance human quality of life. To do so, the CA framework has been modified into a dynamic conceptual framework. Each step of this dynamic framework has been depicted and detailed through a simple model. Then, by using this framework, the ASW of Sado was analysed. The analysis of Sado sustainable agriculture practices showed the usefulness of the CA dynamic framework to articulate the different situations of capability and choice behaviour among farmers. It also aids to examine desirable capability changes and plan necessary interventions, which contribute to the community's participatory deliberation for fair and sustainable management of ASWs.

\section{References}

Alkire, S. (2002) Valuing Freedom: Sen's Capability Approach and Poverty Reduction, Oxford University Press, Oxford.

Bambaradeniya, C.N.B. et al. (2003) 'Biodiversity associated with an irrigated rice agro-ecosystem in Sri Lanka', Biodiversity and Conservation, Vol. 13, No. 9, pp.1715-1753.

Crocker, D. (2006) 'Sen and deliberative democracy', in Kaufman, A. (Ed.): Capabilities Equality: Basic Issues and Problems, pp.155-197, Routledge, London.

Crocker, D. (2008) 'Agency, functioning, and capability', Ethics of Global Development: Agency, Capability, and Deliberative Democracy, pp.150-184, Cambridge University Press, Cambridge.

Devereux, S. (2001) 'Sen's entitlement approach: critiques and counter-critiques', Oxford Development Studies, Vol. 29, No. 3, pp.245-263.

Elphick, C.S. (2000) 'Functional equivalency between rice fields and seminatural wetland habitats', Conservation Biology, Vol. 14, No. 1, pp.181-191.

Endo, C. and Nagata, H. (2013) 'Seasonal changes of foraging habitats and prey species in the Japanese crested ibis-Nipponia Nippon reintroduced on Sado Island, Japan', Bird Conservation International, Vol. 23, No. 4, pp.445-453.

Fukuda-Parr, S. (2003) 'The human development paradigm: operationalizing Sen's ideas on capabilities', Feminist Economics, Vol. 9, Nos. 2-3, pp.301-317.

Gasper, D. (2002) 'Is Sen's capability approach an adequate basis for considering human development?', Review of Political Economy, Vol. 14, No. 4, pp.435-461.

Gotoh, R. (2002) Economical Philosophy for Justice - Rawls and Sen, in Japanese, Toyo Keizai Shinposha, Tokyo.

Gotoh, R. (2014) 'Re-conceptualization of the capability approach - opportunity, autonomy and identity', Economic Review, Vol. 65, No. 4, pp.318-331, Hitotsubashi University. 
Holland, B. (2008) 'Ecology and the limits of justice: establishing capability ceiling in Nussbaum's capabilities approach', Journal of Human Development, Vol. 9, No. 3, pp.401-425.

Ishii, S. et al. (1994) 'Endocrinological studies for artificial breeding of the Japanese ibis, Nipponia nippon, an endangered avian species in Asia', J. Biosci., Vol. 19, No. 4, pp.491-502.

Lessmann, O. and Rauschmayer, F. (2013) 'Re-conceptualizing sustainable development on the basis of the capability approach: a model and its difficulties', Journal of Human Development and Capabilities, Vol. 14, No. 1, pp.95-114.

MOE Reintroduction Center (2008) The Japanese Crest Ibis Information [online] https://blog.goo. ne.jp/tokimaster/e/02035e42dd497cf6939fd9e538539752 (accessed 13 September 2019).

Nussbaum, M. (2000) Women and Human Development: The Capabilities Approach, Cambridge University Press, Cambridge.

Nussbaum, M. (2011) Creating Capabilities: The Human Development Approach, Belknap Press, Cambridge.

Oda, M. and Kiminami, L. (2014) 'Study on the consciousness of the farm households introducing environment-friendly agriculture', Bulletin of the Faculty of Agriculture, Niigata University, Vol. 2, No. 66, pp.85-104.

Ogawa, Y. and Sakai, K. (1985) 'Effects of nitrate enrichment of irrigation water on nitrogen balance in a paddy field', Japanese Journal of Soil Science and Plant Nutrition, Vol. 56, No. 1, pp.1-9.

Robeyns, I. (2005) 'The capability approach: a theoretical survey', Journal of Human Development, Vol. 6, No. 1, pp.93-117.

Sen, A. (1981) Poverty and Famines: An Essay on Entitlement and Deprivation, Clarendon Press, Oxford.

Sen, A. (1985a) Commodities and Capabilities, Oxford University Press, North-Holland, Amsterdam.

Sen, A. (1985b) 'Well-being, agency and freedom - the Dewey lectures 1984', The Journal of Philosophy, Vol. 82, No. 4, pp.169-221.

Sen, A. (1992) Inequality Reexamined, Harvard University Press, Cambridge.

Sen, A. (1999) Development as Freedom, Oxford University Press, Oxford.

Sen, A. (2004) 'Why we should preserve the spotted owl', The London Review of Books, Vol. 25, No. 3, pp.10-11.

Sen, A. (2013) 'The ends and means of sustainability', Journal of Human Development and Capabilities, Vol. 14, No. 1, pp.6-20.

The Stockholm Convention on Persistent Organic Pollutants (2001) [online] http://www.pops.int/ TheConvention/Overview/History/Overview/tabid/3549/Default.aspx (accessed 13 September 2019).

The World Commission on Environment and Development (1987) [online] https://sustainabledevelopment.un.org/milestones/wced (accessed 17 March 2020).

UNESCO World Heritage List [online] https://whc.unesco.org/en/list/722, https://whc.unesco.org/ en/list/1111 (accessed 13 September 2019).

Yamane, F. et al. (2003) 'Economic evaluation of the groundwater conservation policy by residents in Kumamoto City', Journal Rural Planning Association, Vol. 22, No. 3, pp.203-208. 